\title{
Hyper Secretion of GH: Pituitary Gigantism
}

\section{Anne Ballin}

Center for Health Sciences and Primary Care, Netherlands.

*Corresponding Author : Anne Ballin, Center for Health Sciences and Primary Care, Netherlands. Email: anne.Ballin@umcutrecht.nl Received date: January 02, 2018;Accepted date : January 10, 2018; Published date: January 17, 2018

Citation for this Article : Anne Ballin, Hyper Secretion of GH: Pituitary Gigantism, J. Endocrinology and Disorders. Doi: 10.31579/2640-1045/017

Copyright : (C) 2018 Anne Ballin.This is an open-access article distributed under the terms of the Creative Commons Attribution License, which permits unrestricted use, distribution, and reproduction in any medium, provided the original author and source are credited.

\section{Key words}

Galactorrhoea; Snoring; Gigantism; Acromegaloid

\section{Introduction}

Gigantism refers to a condition characterized by extreme physical size and stature. By definition, this originates during infancy, childhood or adolescence, when epiphyseal growth plates remain open. Although the term gigantism may be applied to a number of non-hormonally mediated overgrowth conditions in children, it is often used to specifically denote growth hormone $(\mathrm{GH})$ excess. GH excess during childhood and adolescence is extremely rare, with the total number of reported cases thus far numbering only in the hundreds. Herein we present such a case.

\section{Case Report}

This 25-year-old lady,hailing from a rural area of West Bengal, presented to us with history of increased statural growth and enlarged body parts noticed since the age of 14 years, primary amenorrhea, and frontal headache for the last 2 years. She has also been suffering from non-inflammatory low back pain with progressive kyphosis and pain in the knees, ankles and elbows for the last 5 years. At the time of presentation, she was unable to walk without assistance. There was no history of visual disturbance, vomiting, galactorrhoea, cold intolerance, acroparaesthesia, overt gastrointestinal bleeding, or snoring. She had no siblings. There was no history of similar illness in the family.

On examination, vitals were stable with normal blood pressure. Height was $221 \mathrm{~cm}$; weight was $138 \mathrm{~kg}$ with BMI of 28 . There was coarsening of facial features along with frontal bossing and prognathism. She had large hands and feet Her voice was deep. There was a small goitre. Patient could not stand straight due to severe kyphosis and osteoarthritis of knees with limited joint mobility. Osteoarthritic changes were also present in the small joints of the hand. Confrontation perimetry suggested bitemporal hemianopia. There was no visceromegaly. Breast was Tanner stage 1, and there was no axillary or pubic hair.

Laboratory investigation showed OGTT of $136 \mathrm{mg} / \mathrm{dl}$ with normal liver and renal function test. Serum IGF1 was $703 \mathrm{ng} / \mathrm{ml}$ with all glucose suppressed GH values of $>40 \mathrm{ng} / \mathrm{ml}$. Prolactin was $174 \mathrm{ng} / \mathrm{ml}$. Basal cortisol and thyroid profile were normal. Pooled sera showedFSH of 1.05 and LH of $0.272 \mathrm{mIU} / \mathrm{ml}$. Serum calcium, and phosphorus were normal. iPTH was $16.7 \mathrm{pg} / \mathrm{ml}$. Hemoglobin was 11.1 $\mathrm{g} / \mathrm{dl}$. Computed tomographyscan of brain showed large pituitary macroadenoma. Magnetic resonance imaging (MRI) could not be done as the patient could not be negotiated within the MRI machine. Automated perimetry confirmed bitemporal hemianopia. ultrasound (USG) showed small, prepubertaluterine volume $(1.5 \mathrm{ml})$.
X-rays showed osteoarthritic changes of spine, knees, and small joints of the hand. Epiphyses were seen to be fused in X-rays of hands and knees.

A diagnosis of gigantism due to $\mathrm{GH}$ secreting pituitary macroadenoma with hypogonadotrophichypogonadism was made. Debulkingpituitary surgery followed by somatostatinanalogue therapy with gonadal steroid replacement had been planned, but the patient refused further treatment.

\section{Discussion}

Gigantism is an extremely rare condition caused by hypersecretion of GH.In 1909, when Harvey Cushing examined the skeleton of an Irish patient who lived from 1761-1783, he noted an enlarged pituitary fossa.[1] Subsequently it has been observed that GH hypersecretion in childhood is usually caused by pituitary adenoma or hyperplasia.[2] Gigantism differs from the acromegaly by the time of onset, i.e. before and after epiphyseal fusion respectively. This condition may occur sporadically or may show familial predilection. Extreme tall stature is very rare nowadays because of early presentation and treatment. Acromegaloid features may develop in older children.[3] The most consistent biochemical abnormality observed in patients with gigantism is an elevated IGF-1. The gold standard for making the diagnosis of $\mathrm{GH}$ excess relies on the inability to suppress serum GH to an appropriate level (usually $<1 \mathrm{ng} / \mathrm{ml}$ ) following $75 \mathrm{~g}$ oral glucose load. Hyperprolactinemia is also commonly seen, which is usually due to co-secretion by mammosomatotroph.

\section{References}

1. Chahal HS, Stals K, Unterländer M, Balding DJ, Thomas MG, Kumar AV, et al. AIP mutation in pituitary adenomas in the $18^{\text {th }}$ century and today. N Engl J Med. 2011;364:43-50.

2. de Herder WW. Acromegaly and gigantism in the medical literature. Case descriptions in the era before and the early years after the initial publication of Pierre Marie (1886) Pituitary. 2009;12:236-44.

3. Gagel RF, McCutcheon IE. Images in clinical medicine. Pituitary gigantism. N Engl J Med. 1999;340:524. 